\title{
Microstructure and physical properties of the multicomponent PZT- type ceramics doped by calcium, sodium, bismuth and cadmium
}

\author{
Dariusz Bochenek $^{1}$ (D) Przemysław Niemiec ${ }^{1}$
}

Received: 3 July 2018 / Accepted: 18 October 2018 / Published online: 26 October 2018

(c) The Author(s) 2018

\begin{abstract}
In this work, the multicomponent $\mathrm{Pb}\left(\mathrm{Zr}_{0.58} \mathrm{Ti}_{0.42}\right) \mathrm{O}_{3}$ ceramics doped by calcium (Ca), sodium (Na), bismuth (Bi) and cadmium (Cd) was designed and obtained by the hot uniaxial pressing method. Comprehensive electrophysical properties including crystalline structure, microstructure, dielectric, electromechanical and piezoelectric of the ceramics were made. The $\mathrm{Pb}_{0.92} \mathrm{Ca}_{0.02} \mathrm{Na}_{0.01} \mathrm{Bi}_{0.05}\left(\mathrm{Zr}_{0.58} \mathrm{Ti}_{0.42}\right)_{0.98} \mathrm{Cd}_{0.02} \mathrm{O}_{3}$ ceramics obtained by the hot uniaxial pressing method has a microstructure of a regularly crystallized grain. The multicomponent material shows high values of dielectric and piezoelectric properties with high ferroelectric hardness. A wide and rectangular hysteresis loop of the PZT-type ceramics shows high ferroelectric hardness of obtained ceramics. Studies have also shown that multicomponent PZT-type ceramics exhibits a strong $S-E$ behavior. The $S-E$ electromechanical loops have characteristic "butterfly wings" shape with high values of mechanical strain. These properties of the obtained material allow its application in the modern microelectronics and micromechatronics, for example, in constructing electromechanical and electroacoustic transducers, piezotransformators, piezoelectric motors, etc.
\end{abstract}

\section{Introduction}

Lead zirconate titanate $\mathrm{Pb}\left(\mathrm{Zr}_{1-x} \mathrm{Ti}_{x}\right) \mathrm{O}_{3}(\mathrm{PZT})$ solid solutions (where $x$ is from 0 to 1 range) which have various distorted perovskite-type structures are the most functional and very important piezoelectric materials in modern microelectronic and micromechatronic applications [1-6]. Materials of this broad family are widely used in piezoelectric sensors, electromechanical transducers, microactuators, resonators and filters, computer memory, and display [7-15].

At room temperature, the PZT phase diagram in a simplified way can be described in three basic areas [16-19]. The rhombohedral Zr-rich area (noted Re) is separated from the tetragonal Ti-rich one (noted $\mathrm{T}$ ) by a morphotropic phase boundary (noted MPB). In the MPB, two tetragonal and rhombohedral phases coexist and the PZT-type compositions of this region show excellent dielectric and piezoelectric properties [19-21]. The width of this zone is not clearly established and also it depends on the dopants used and amounts thereof $[22,23]$. Above the Curie temperature the

Dariusz Bochenek

dariusz.bochenek@us.edu.pl

Faculty of Computer Science and Material Science, Institute of Technology and Mechatronics, University of Silesia in Katowice, 12, Żytnia St., 41-200 Sosnowiec, Poland compounds crystallized in a paraelectric cubic phase (with space group P $m 3 m$ ).

To improve their electrophysical properties, the PZTbased compound is subjected to a dopant. The addition of the two, the third, the fourth and more components, the piezoelectric properties can be adjusted over a wide range [19, 23-28]. Compared to the undoped PZT ceramics, multicomponent compounds have many merits such as very high (or very low) electrophysical properties. Another way to get better and optimal properties of the PZT-type material is the use of special technics and methods for the preparation of ceramics, which can be conducted in parallel with doping, among them mainly hot pressing [29], co-precipitation chemical process [30], sol-gel method [31, 32], hydrothermal reaction [33], etc.

In this work, the multicomponent PZT-type ceramics doped by calcium $(\mathrm{Ca})$, sodium $(\mathrm{Na})$, bismuth $(\mathrm{Bi})$ and cadmium (Cd) was designed and obtained. The technology conditions have been optimized as well as the study of physical parameters (crystal structure, microstructure, dielectric, piezoelectric, electric conductivity) was conducted on the ceramic specimens. 


\section{Experiment}

The ceramic powder of the multicomponent $\mathrm{Pb}_{0.92} \mathrm{Ca}_{0.02} \mathrm{Na}_{0.01} \mathrm{Bi}_{0.05}\left(\mathrm{Zr}_{0.58} \mathrm{Ti}_{0.42}\right)_{0.98} \mathrm{Cd}_{0.02} \mathrm{O}_{3}$ material was obtained the hot uniaxial pressing method. The starting powders were simple oxides, $\mathrm{PbO}$ ( $\mathrm{POCH} 99.99 \%$ purity), $\mathrm{ZrO}_{2}$ (ALDRICH 99.50\% purity), $\mathrm{TiO}_{2}$ (MERCK 99.99\% purity), $\mathrm{Bi}_{2} \mathrm{O}_{3}$ (ALFA AESAR $99.999 \%$ purity), $\mathrm{CdO}$ (Sigma-Aldrich $99.9 \%$ purity) as well as carbonates $\mathrm{CaCO}_{3}$ (POCH $99.99 \%$ purity) and $\mathrm{Na}_{2} \mathrm{CO}_{3}$ (SigmaAldrich $\geq 99.0 \%$ purity). The starting ceramic powders were milled using planetary mill FRITSCH Pulverisette 6 by wet method (in ethyl alcohol, by 12 h). After drying, the mixture of powders was compacted into disks and synthesized in the following conditions: a temperature of $950{ }^{\circ} \mathrm{C}$ for time $8 \mathrm{~h}$. After the synthesis, the material was ground, mixed and then the powder was compressed into disks $(10 \mathrm{~mm} / 5 \mathrm{~mm}$, diameter/thickness). The compacting (densifications) of the PZT-type ceramic specimens was made by a hot uniaxial pressing method $\left(T_{\mathrm{s}}=1250\right.$ ${ }^{\circ} \mathrm{C} / t_{\mathrm{s}}=2 \mathrm{~h} / p_{\mathrm{s}}=20 \mathrm{MPa}$, air atmosphere). The final steps of technology PZT-type ceramic specimens were grinding, polishing, removing mechanical stresses (annealing at temperature $700{ }^{\circ} \mathrm{C}$ ) and for electrical testing putting silver paste electrodes onto both surfaces of the specimens.

$\mathrm{X}$-ray measurements of the crystal structure were made on the Phillips diffractometer at room temperature. Energy-dispersive spectrometry (EDS) and electron probe microbeam analysis (EPMA) studies as well as the SEM microstructure of fracture of the ceramic samples were carried out by a JEOL JSM-7100 TTL LV Field Emission Scanning Electron Microscope. This microscope is equipped with an electron gun with a thermal field emission (FE-T). Dielectric measurements (dielectric permittivity and dielectric loss) were conducted in the heating cycle using the capacity bridge of a QuadTech 1920 Precision LCR Meter type (heating rate of $1 \% \mathrm{~min}$, at temperature range from 20 to $500{ }^{\circ} \mathrm{C}$ and in the frequency range from $100 \mathrm{~Hz}$ to $200 \mathrm{kHz}$ ). Measurements of DC electric conductivity were performed using a 6517B Keithley electrometer in the temperature range from 20 to $450{ }^{\circ} \mathrm{C}$.

Hysteresis $(P-E)$ loops were performed using a Sawyer-Tower circuit and a high-voltage amplifier (Matsusada Inc. HEOPS-5B6 Precision). Electromechanical measurements were carried out using an optical displacement meter (Philtec Inc., D63) and a HEOPS-5B6 high-voltage amplifier. The data were stored on a computer disc using an $\mathrm{A} / \mathrm{D}, \mathrm{D} / \mathrm{A}$ transducer card and the LabView computer program.

To test piezoelectric parameters, the ceramic samples were polarized by a low-temperature method (high voltage) using a Matsusada Precision Inc. HEOPS-5B6 high-precision high-voltage amplifier and a Sawyer-Tower circuit (the data were retrieved on a computer disc using an $\mathrm{A} / \mathrm{D}, \mathrm{D} / \mathrm{A}$ transducer card) voltage supply. Poling process was performed in a silicone oil in the following conditions: poling field $E_{\text {pol }}=4.0 \mathrm{kV} / \mathrm{mm}$, poling time $t_{\text {pol }}=1 \mathrm{~h}$ and at poling temperature $T_{\mathrm{pol}}=155^{\circ} \mathrm{C}$. Cooling the sample to room temperature was carried out at an applied electric field.

\section{Results and discussion}

The X-ray examinations confirmed that at room temperature, the multicomponent PZT-type ceramics has perovskite structure (Fig. 1). From Fig. 1, it was found that the material has rhombohedral phase matching with the JCPDS file no. 01-073-2022, close to morphotropy region. The X-ray structure confirmed too that material has single perovskitetype phase, without foreign, undesirable phases (for example, pyrochlore phase). The ceramic sample has high a mass density of $\rho=7.83 \mathrm{~g} / \mathrm{cm}^{3}$.

The SEM images of the multicomponent PZT-type ceramics are shown in Fig. 2a and they show that the microstructure of this material is very dense. The obtained ceramic sample has high density (Table 1). The microstructure of fracture is characterized by well-crystallized, shapely and regular grains with a high degree of homogeneity. An average grain size for multicomponent PZT ceramics is between 3 and $4 \mu \mathrm{m}$. The high degree of uniformity of grain in ceramic microstructure was obtained using sintering by hot uniaxial pressing.

This sintering method used during technological process allows gain for so-called texture effect. In the microstructure, grain boundaries are characterized by sharp edges and fracture takes place through grain boundaries, indicating greater mechanical strength interiors of the grains in comparison with the grain boundaries. Defected grain boundaries form

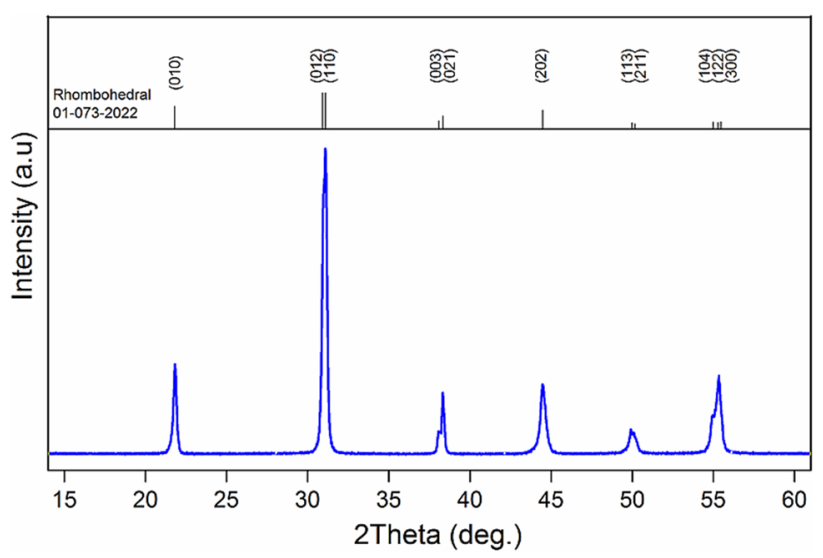

Fig. 1 The X-ray spectra of the multicomponent PZT-type ceramics 

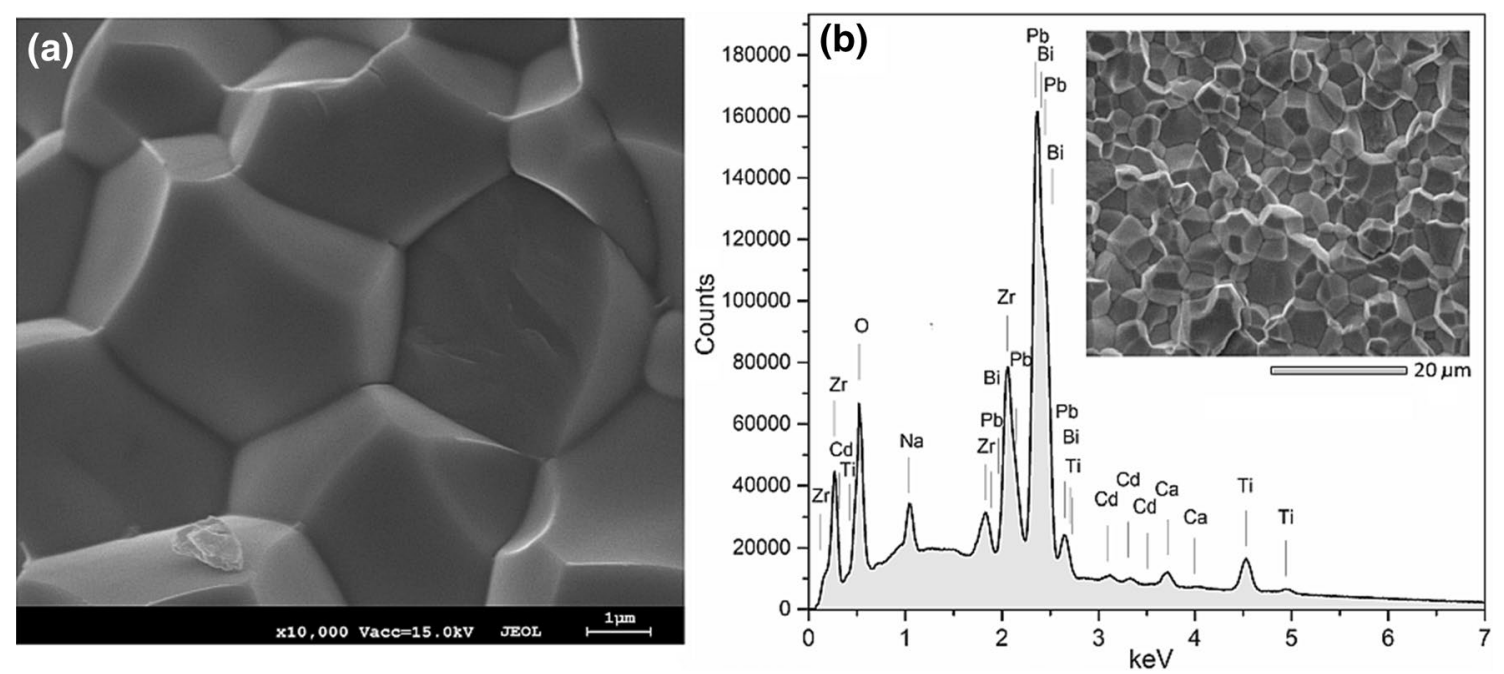

Fig. 2 SEM images (a) and EDS analysis image of the element distribution (b) for the multicomponent PZT-type ceramics

Table 1 The dielectric and piezoelectric parameters of the multicomponent PZT-type ceramics (at a room temperature)

\begin{tabular}{ll}
\hline Parameter & PZT-type ceramics \\
\hline$\rho\left(\mathrm{g} / \mathrm{cm}^{3}\right)^{\mathrm{a}}$ & 7.83 \\
$T_{\mathrm{C}}\left({ }^{\circ} \mathrm{C}\right)^{\mathrm{b}}$ & 357 \\
$\varepsilon$ at $T_{\mathrm{r}}{ }^{\mathrm{b}}$ & 695 \\
$\tan \delta$ at $T_{\mathrm{r}}{ }^{\mathrm{b}}$ & 0.030 \\
$\varepsilon$ at $T_{\mathrm{C}}{ }^{\mathrm{b}}$ & $52,170.00$ \\
$\tan \delta$ at $T_{\mathrm{C}}{ }^{\mathrm{b}}$ & 0.055 \\
$P_{\mathrm{r}}\left(\mu \mathrm{C} / \mathrm{cm}^{2}\right)^{\mathrm{c}}$ & 43.30 \\
$P_{\mathrm{s}}\left(\mu \mathrm{C} / \mathrm{cm}^{2}\right)^{\mathrm{c}}$ & 45.11 \\
$E_{\mathrm{c}}\left(\mathrm{kV} / \mathrm{mm}^{\mathrm{c}}\right.$ & 1.13 \\
$a_{\mathrm{rec}}$ & 1.077 \\
$k_{\mathrm{p}}$ & 0.61 \\
$k_{31}$ & 0.32 \\
$d_{31}(\mathrm{C} / \mathrm{N})$ & $89.92 \times 10^{-12}$ \\
$g_{31}(\mathrm{Vm} / \mathrm{N})$ & $16.94 \times 10^{-3}$ \\
$S^{\mathrm{E}}\left(\mathrm{m}^{2} / \mathrm{N}\right)$ & $1.23 \times 10^{-11}$ \\
$V_{\mathrm{r}}(\mathrm{m} / \mathrm{s})$ & 2065 \\
$Q_{\mathrm{m}}$ & 51 \\
$d_{33}^{*}(\mathrm{pC} / \mathrm{N})^{\mathrm{d}}$ & 185 \\
\hline
\end{tabular}

${ }^{\mathrm{a}}$ Mass density (mass/volume)

${ }^{\mathrm{b}}$ For $v=1 \mathrm{kHz}$

${ }^{\mathrm{c}}$ For $v=1 \mathrm{~Hz}$ and $E=2.3 \mathrm{kV} / \mathrm{mm}$

${ }^{\mathrm{d}}$ For $E=2.0 \mathrm{kV} / \mathrm{mm}$

narrow transitional areas between adjoining neighboring crystal grains with different crystal orientations. In a typical case, the ceramic grains of a microstructure usually have walls with four, five and six sides. In fact, the number of walls of individual grains in the microstructure has generally large variations, and usually varies from a few to several walls. In the case of undoped $\mathrm{Pb}\left(\mathrm{Zr}_{0.58} \mathrm{Ti}_{0.42}\right) \mathrm{O}_{3}$ ceramics, the microstructure is characterized by a grain of high heterogeneity and an average grain size of 5-7 $\mathrm{mm}[34,35]$. The EDS analysis of the element distribution made on the surface of the PZT sample confirmed both qualitative and quantitative contents of particular initial components used to obtain this material. This analysis included measurement of ten randomly selected areas of the surface sample (Fig. 2b).

At room temperature, the multicomponent PZT-type ceramics exhibit low $\sigma_{\mathrm{DC}}$ electric conductivity (high value of resistivity). Temperature measurement of the DC electrical conductivity was conducted in the temperature range from room temperature to $450{ }^{\circ} \mathrm{C}$ (Fig. 3). From room temperature to approx. $360{ }^{\circ} \mathrm{C}$, slow growth in the $\sigma_{\mathrm{DC}}$ value occurs (Fig. 3a). Above a temperature of $360{ }^{\circ} \mathrm{C}$, a significant increase in the $\sigma_{\mathrm{DC}}$ value is observed (increase of electrical conductivity above phase transition). The $\ln \sigma_{\mathrm{DC}}$ (1000/T) graph (Fig. 3b) shows change values of that activation energy at low temperature (I) and at high temperature (II) (change inflection of the curve in this areas). In these characteristic areas, $E_{\mathrm{Act}}$ values of activation energy were calculated according to the Arrhenius law [36]:

$\sigma_{\mathrm{DC}}=\sigma_{0} \mathrm{e}^{-\frac{E_{\mathrm{Act}}}{k_{\mathrm{B}} T}}$,

where $k_{\mathrm{B}}$ is the Boltzmann constant, $E_{\mathrm{Act}}$ is the activation energy, and $T$ is the absolute temperature. The values of activation energy are summarized in Fig. $3 \mathrm{~b}$. In the above temperature range of the phase transition, the value of $E_{\mathrm{Act}}$ is higher compared to the value of $E_{\mathrm{Act}}$ at low temperatures, which is characteristic of the materials with perovskite-type structure.

The temperature dependencies of the dielectric permittivity for the obtained ceramics are presented in Fig. 4. 

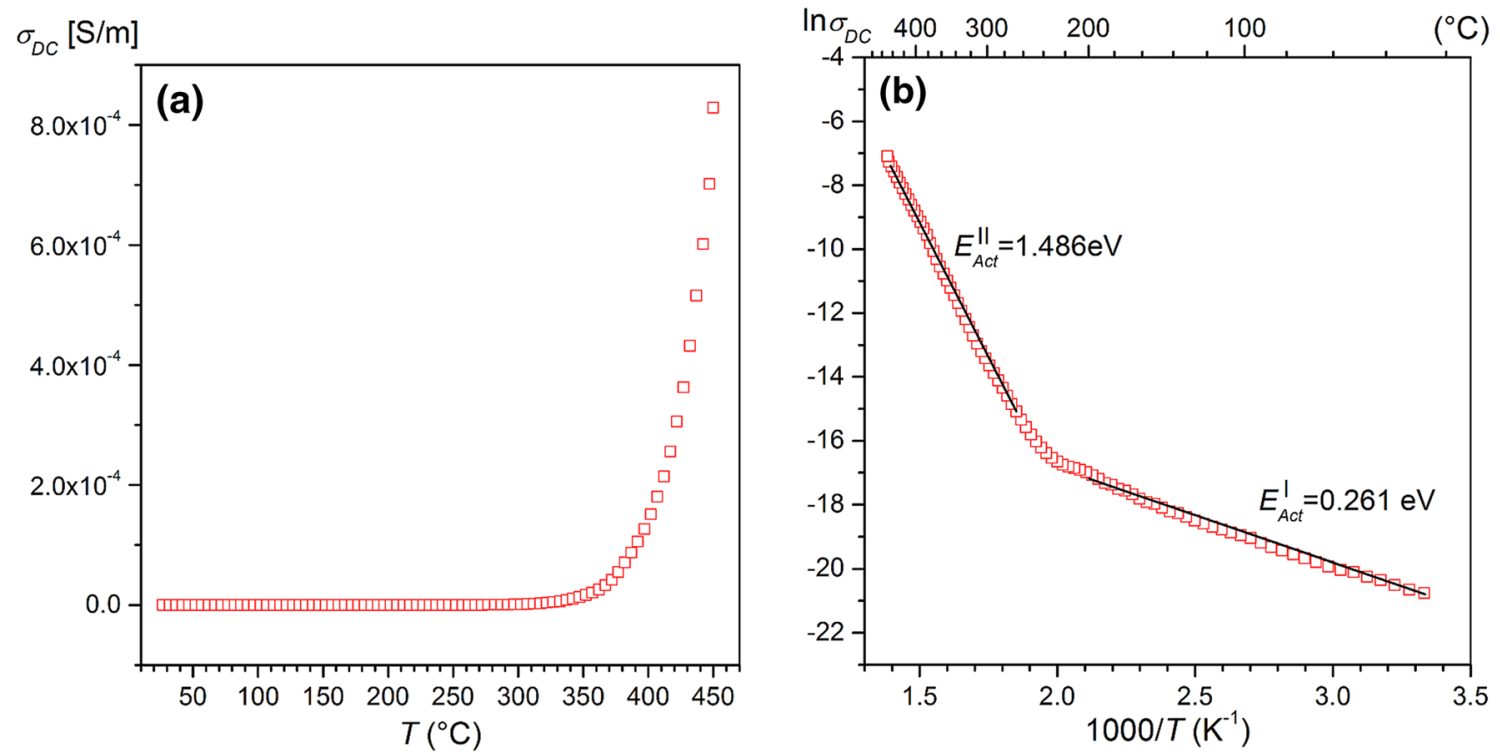

Fig. 3 The $\sigma_{\mathrm{DC}}(T)(\mathbf{a})$ and the $\ln \sigma_{\mathrm{DC}}(1000 / T)$ relationship for the multicomponent PZT-type ceramics $(\mathbf{b})$

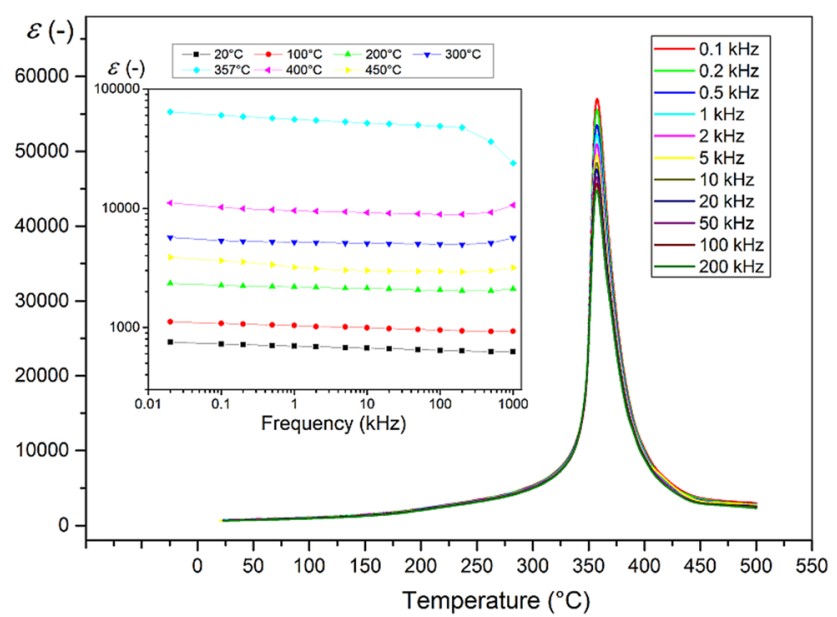

Fig. 4 The $\varepsilon(T)$-temperature relationships for multicomponent PZTtype ceramics (a heating cycle). Inset: frequency dependencies of dielectric permittivity

Material is characterized by high values of the maximum of electric permittivity at temperature of the phase transition as well as at room temperature (Table 1). Obtained ceramics shows sharp (pointed) phase transition from the ferroelectric to paraelectric phase (there is not a distinct shift in the phase transition temperature from the change of the measurement frequency). This proves the high physical and chemical heterogeneities of the ceramic samples and confirms the correct conduct of the technological process. The frequency dependencies of dielectric permittivity of the obtained ceramics at various temperatures (from 100 to $450{ }^{\circ} \mathrm{C}$ ) are presented in Fig. 4 (inside). It is clear that dielectric permittivity decreases with the increase of frequency

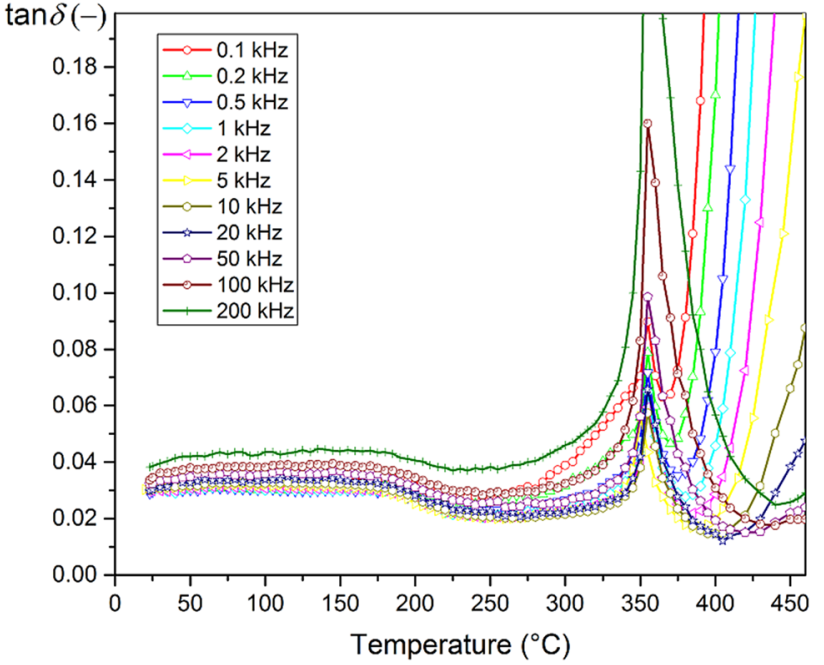

Fig. 5 Temperature dependencies of the $\tan \delta$ for the multicomponent PZT-type ceramics (a heating cycle)

of the measurement field, and it attains a constant value at high frequencies (at low-temperature region). At high temperatures are observed deflections from this correctness. The high values of dielectric permittivity at low frequencies may be associated with the dipoles that result from changes in the valence states of the cations, as well as with the formation of the space charge polarization due to the inhomogeneous microstructure (in polycrystalline ceramic sample, heterogeneity is associated with factors such as impurities, pores, grains and grain boundaries) [37].

In the obtained material, high values of the dielectric permittivity are accompanied by low dielectric loss at 
temperature region from $20{ }^{\circ} \mathrm{C}$ to about $350{ }^{\circ} \mathrm{C}$ (Fig. 5). On the temperature dependencies of the dielectric loss, the characteristic peaks (characteristic maxima for perovskite PZT-type materials) for ferroelectric-paraelectric phase transition are observed close to each other. These peaks for all frequencies occur at a temperature of $357^{\circ} \mathrm{C}$. Above this temperature, there is a slight decrease in the value of dielectric loss and then rapid growth (connected with an increase in electric conductivity at high temperatures).

The multicomponent PZT-type ceramics exhibits a typical square hysteresis loop (Fig. 6a) with high values of the saturation polarization $\left(P_{\mathrm{s}}\right)$ and remnant polarization $\left(P_{\mathrm{r}}\right)$, obtained at relatively low electric field $(E=2.0 \mathrm{kV} / \mathrm{mm})$. At room temperature and frequency $1 \mathrm{~Hz}$, this material has a wide hysteresis loop (a coercive field is $E_{\mathrm{C}}=1.33 \mathrm{kV} / \mathrm{mm}$ ) with residual polarization equal $P_{\mathrm{r}}=43.3 \mu \mathrm{C} / \mathrm{cm}^{2}$. A wide and rectangular hysteresis loop shows high ferroelectric hardness of obtained ceramics. In comparison with undoped $\mathrm{Pb}\left(\mathrm{Zr}_{0.58} \mathrm{Ti}_{0.42}\right) \mathrm{O}_{3}$ ceramics [31, 38], the multicomponent PZT-type ceramics shows much higher value of $P_{\mathrm{r}}$, obtained at relatively low electric field. Increase in the frequency of the measuring field slightly expands the hysteresis loop and reduces values of the residual polarization and maximum polarization (Fig. 6b).

The temperature hysteresis $(P-E)$ loops for the obtained ceramics (for frequency $v=1 \mathrm{~Hz}$ and for maximum of electric field $E=2.3 \mathrm{kV} / \mathrm{mm}$ ) are presented in Fig. 7. With increasing temperature, $P-E$ loops become narrower and residual polarization decreases (Fig. 8). Increase in temperature results in an increased saturation of the ferroelectric

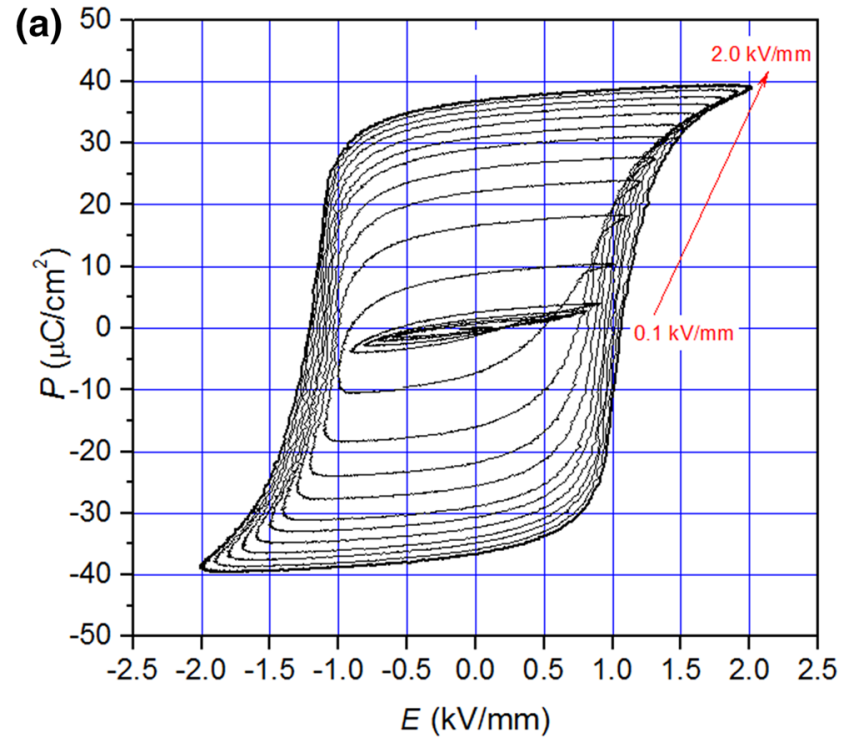

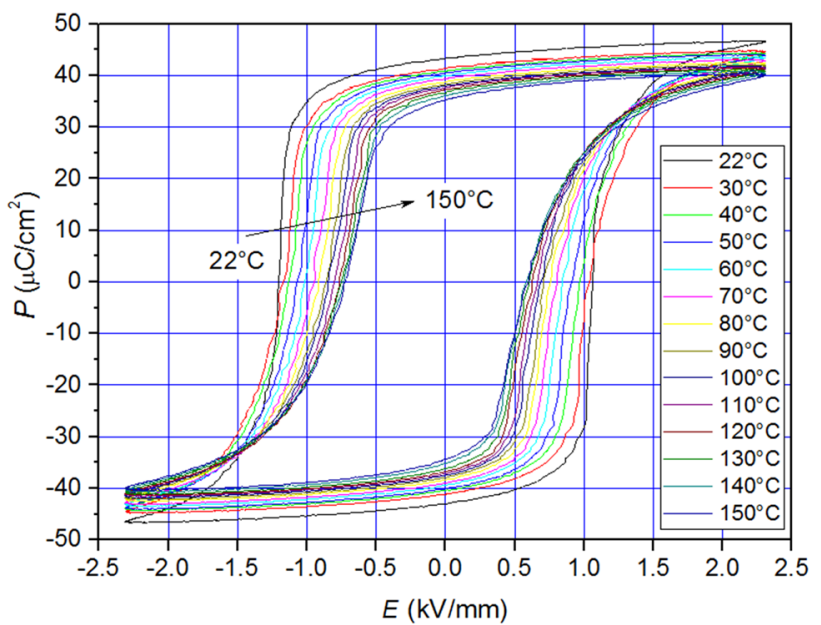

Fig. 7 The temperature hysteresis loops for the multicomponent PZTtype ceramics $(v=1 \mathrm{~Hz})$

hysteresis loop too. Rectangularity coefficient of the hysteresis loop was calculated from the following formula:

$a_{\mathrm{rec}}=\frac{P_{\mathrm{r}}}{P_{\max }}$,

and the $a_{\text {rec }}$ value at room temperature is presented in Table 1. Increase of temperature results in the rectangularity coefficient (Fig. 8).

The $S(E)$ electromechanical tests of an unpolarized sample measured in the applied electric field range $1.0-2.0 \mathrm{kV} /$ $\mathrm{mm}$ and at room temperature are presented in Fig. 9. The

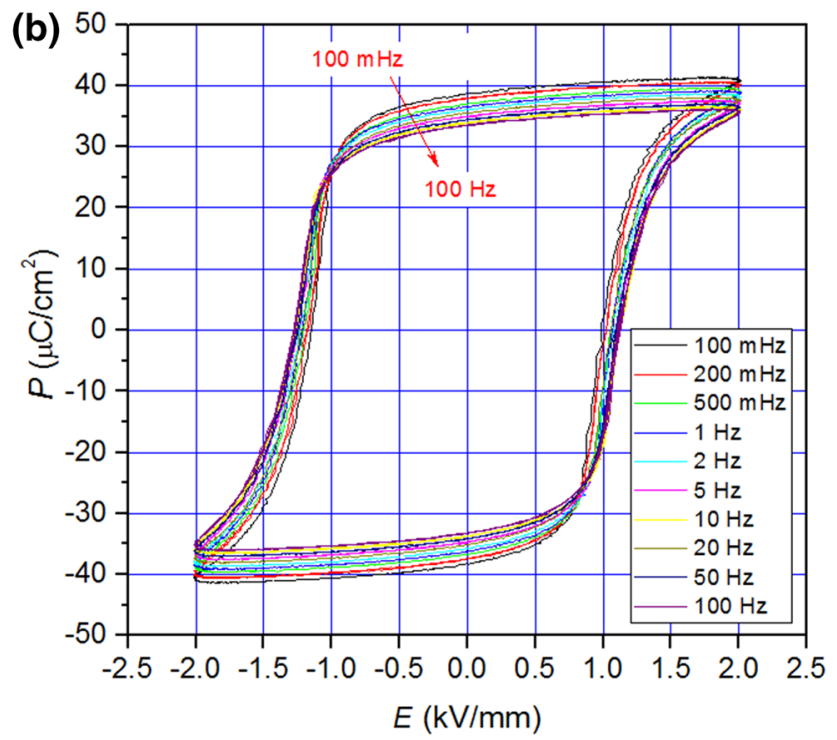

Fig. 6 The hysteresis loops at room temperature for the multicomponent PZT-type ceramics $\mathbf{a}$ at various electric fields and $\mathbf{b}$ at various frequencies 


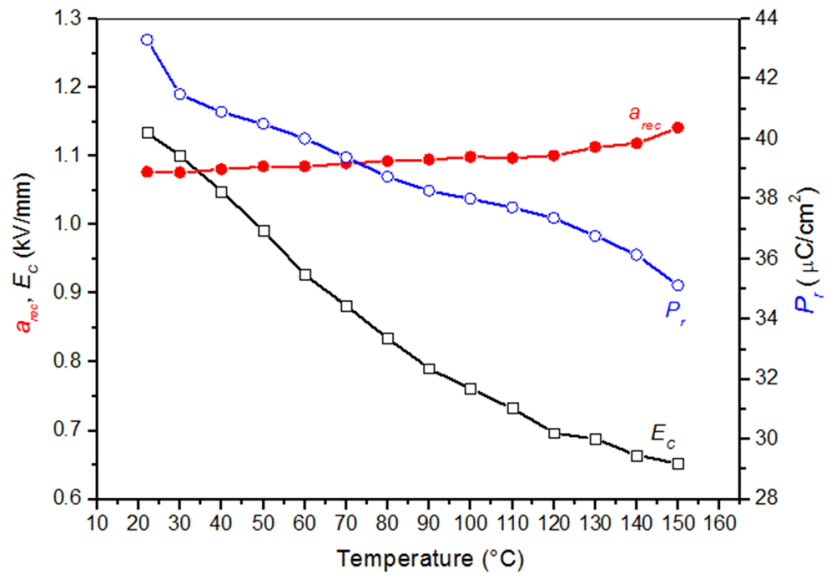

Fig. 8 Temperature changes of the $E_{\mathrm{c}}, P_{\mathrm{r}}$ and $a_{\mathrm{rec}}$ for the multicomponent PZT-type ceramics

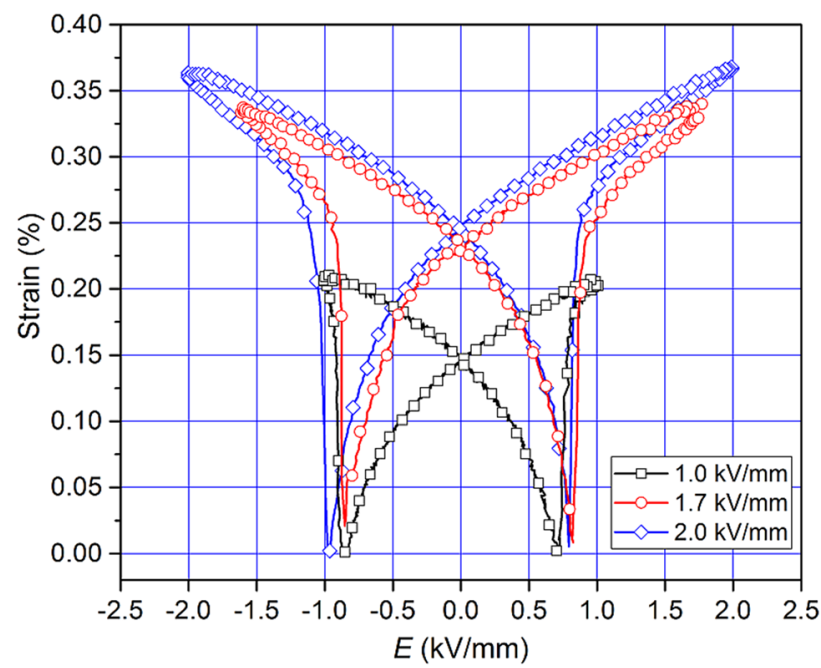

Fig. 9 The bipolar strain-electric field loops $(S-E)$ for the multicomponent PZT-type ceramics measured in the applied electric field range $1.0-2.0 \mathrm{kV} / \mathrm{mm}(v=0.1 \mathrm{~Hz})$

$S-E$ electromechanic loops have characteristic "butterfly wings" shape with high values of mechanical strain. The value of remnant strain $S_{\mathrm{r}}$ measured by the butterfly curve is $0.15 \%, 0.23 \%$ and $0.25 \%$ for applied electric field $1.0 \mathrm{kV} /$ $\mathrm{mm}, 1.7 \mathrm{kV} / \mathrm{mm}$ and $2.0 \mathrm{kV} / \mathrm{mm}$, respectively. The value of strain for the maximum of the applied electric field increases from 0.20 to $0.37 \%$ when the applied electric field increases from $1.0 \mathrm{kV} / \mathrm{mm}$ to $2.0 \mathrm{kV} / \mathrm{mm}$.

The ceramic sample of the multicomponent PZT-type ceramics exhibits a strong $S-E$ behavior. This may be due to the increase in domain switching as the motion of domain walls becomes easier with increased applied electric field. The rate of domain switching is increased with the increase of the applied electric field, which can cause a significant increase in strain [39]. The obtained multicomponent PZT-type ceramics has high value of $d_{33}^{*}$-corresponding effective piezoelectric coefficient (Table 1) which characterized good piezomaterials. The $d_{33}^{*}$-corresponding effective piezoelectric coefficient was calculated according to the below formula [39] and based on $S-E$ loop (for frequency $0.1 \mathrm{~Hz}$ and applied electric field $2.0 \mathrm{kV} / \mathrm{mm})$ :

$d_{33}^{*}=\frac{S_{\max }}{E_{\max }}$,

where $d_{33}^{*}$ is corresponding effective piezoelectric coefficient, $S_{\max }$ is maximum value of mechanical strain, and $E_{\max }$ is maximum value of electric field.

The impact of introduced admixtures on the electrophysical properties of multicomponent PZT-type ceramics should be considered in a holistic way. Homo- or heterovalent cations of ionic radii near the cations replaced are used mainly for the substitution in materials with perovskite-type structures. In the ideal perovskite structure, there are two cations for every three atoms, and the resultant oxidation states of the cations and anions become zero. However, there are a lot of compounds and solid solutions of the perovskite-type structure for which the composition stoichiometry is retained. High values of dielectric and piezoelectric properties of obtained ceramics are achieved thanks to the $\mathrm{Bi}^{3+}$-doped bismuth and $\mathrm{Ca}^{2+}$. The ferroelectric hardness is achieved primarily through the use of hard-doped sodium ions $\left(\mathrm{Na}^{+}\right)$introduced in position A of the compound. This results in high values of coercivity field, density and piezoelectric properties. The cadmium admixture added to PZT-type materials leads to an increase in $\varepsilon$ and $k_{\mathrm{p}}$, although it increases the value of the dielectric $\operatorname{loss}(\tan \delta)$ as well.

The poled state is important for technical applications, since it exhibits an approximately linear piezoelectric behavior for electric fields with small amplitude. The multicomponent PZT-type ceramics exhibit much better electrophysical parameters compared to an undoped material with a base $\mathrm{Pb}\left(\mathrm{Zr}_{0.58} \mathrm{Ti}_{0.42}\right) \mathrm{O}_{3}$ composition [34, 35, 38]. A much better set of functional parameters is extremely important in the case of piezoelectric applications in modern microelectronics. Piezoelectric parameters of ceramic sample after poling process were measured by resonance-antiresonance method. Obtained multicomponent PZT-type ceramics has high values of piezoelectric parameters of the electrical coupling coefficient $k_{\mathrm{p}}=0.61$, the piezoelectric coefficient $d_{31}=89.92 \times 10^{-12}$ $\mathrm{C} / \mathrm{N}$ and $g_{31}=16.94 \times 10^{-3} \mathrm{Vm} / \mathrm{N}$ (Table 1 ). 


\section{Conclusion}

The multicomponent PZT-type ceramics admixed with calcium $(\mathrm{Ca})$, sodium $(\mathrm{Na})$, bismuth $(\mathrm{Bi})$ and cadmium $(\mathrm{Cd})$ was obtained with success using the hot uniaxial pressing method. Piezoelectric materials used in modern microelectronics and micromechatronics can be classified as smart materials. Such materials change their physical properties under the influence of external factors or they sense the change occurring in the environment and using the feedback system, adapt to correct or eliminate such a change.

The tests carried out for the $\mathrm{Pb}_{0.92} \mathrm{Ca}_{0.02} \mathrm{Na}_{0.01} \mathrm{Bi}_{0.05}\left(\mathrm{Zr}_{0.58} \mathrm{Ti}_{0.42}\right)_{0.98} \mathrm{Cd}_{0.02} \mathrm{O}_{3}$ material show a high-density, fine-grained and non-porous microstructure, which results in the high values of electrophysical and piezoelectric parameters. This may be due to the increase in domain switching as the motion of domain walls becomes easier with increased applied electric field. A wide and rectangular hysteresis loop of the PZT-type ceramics shows high ferroelectric hardness of obtained ceramics. The multicomponent PZT-type ceramics exhibits a strong $S-E$ behavior, too. The $S-E$ electromechanical loops have characteristic "butterfly wings" shape with high values of mechanical strain. The multicomponent PZT-type ceramic shows high ferroelectric hardness resulting in a high resistance to depolarization under the influence of external electric fields and mechanical stresses.

Thanks to these properties, the $\mathrm{Pb}_{0.92} \mathrm{Ca}_{0.02} \mathrm{Na}_{0.01} \mathrm{Bi}_{0.05}\left(\mathrm{Zr}_{0.58} \mathrm{Ti}_{0.42}\right)_{0.98} \mathrm{Cd}_{0.02} \mathrm{O}_{3}$ ceramics is a good candidate for modern applications in constructing electromechanical and electroacoustic transducers, piezotransformators, piezoelectric motors, etc.

Open Access This article is distributed under the terms of the Creative Commons Attribution 4.0 International License (http://creativeco mmons.org/licenses/by/4.0/), which permits unrestricted use, distribution, and reproduction in any medium, provided you give appropriate credit to the original author(s) and the source, provide a link to the Creative Commons license, and indicate if changes were made.

\section{References}

1. M. Venkata Ramana, S. Roopas Kiran, N. Ramamanohar Reddy, K.V. Siva Kumar, V.R.K. Murthy, B.S. Murty, Mater. Chem. Phys. 126, 295 (2011)

2. H. Schmid, J. Phys. Condens. Matter 20, 434201 (2008)

3. J. Kulawik, D. Szwagierczak, B. Gröger, Bull. Pol. Acad. Tech. 55, 293 (2007)

4. Z. Surowiak, D. Bochenek, Arch. Acoust. 33, 243 (2008)

5. R. Sitko, B. Zawisza, J. Jurczyk, D. Bochenek, M. Płońska, Microchim. Acta 144, 9 (2004)
6. K. Uchino, J.R. Giniewicz, Micromechatronics (Marcel Dekker, Inc., New York, 2003), pp. 103-265

7. H.S. Tzou, H.-J. Lee, S.M. Arnold, Mech. Adv. Mater. Struct. 11, 367 (2004)

8. W. Jo, R. Dittmer, M. Acosta, J. Zang, C. Groh, E. Sapper, K. Wang, J. Rödel, J. Electroceram. 29, 71 (2012)

9. S.-Y. Chu, T.-Y. Chen, I.-Ta Tsai, Walter Water Sens.Actuators A 113, 198 (2004)

10. S.L. Fu, S.Y. Cheng, C.C. Wei, Ferroelectrics 67, 93 (1986)

11. J. Deng, W. Zhu, O.K. Tan, X. Yao, Sens. Actuators B 77, 416 (2001)

12. E. Flint, C. Liang, C.A. Rogers, J. Intell. Mater. Syst. 6, 117 (1995)

13. F.P. Sun, Z. Chandhry, C. Liang, C.A. Rogers, J. Intell. Mater. Syst. 6, 134 (1995)

14. Q. Tan, D. Viehland, J. Am. Ceram. Soc. 81, 328 (1998)

15. K. Onitsuka, A. Dogan, J.F. Tressler, Q. Xu, S. Yoshikawa, R.E. Newnham, J. Intell. Mater. Syst. 6, 447 (1995)

16. Y. Xu, Ferroelectric Materials and Their Applications (Elsevier, Amsterdam, 1991), pp. 104-112

17. B. Noheda, D.E. Cox, G. Shirane, J.A. Gonzalo, L.E. Cross, S.-E. Park, Appl. Phys. Lett. 74, 2059 (1999)

18. B. Noheda, J.A. Gonzalo, L.E. Cross, R. Guo, S.-E. Park, D.E. Cox et al., Phys. Rev. B 61, 8687 (2000)

19. C. Bedoya, Ch Muller, J.-L. Baudour, V. Madigou, M. Anne, M. Roubin, Mater. Sci. Eng. B 75, 43 (2000)

20. B. Jaffe, R.S. Roth, S. Marzullo, J. Res. Natl. Bur. Stand. 55, 239 (1955)

21. M.R. Soares, A.M.R. Senos, P.Q. Mantas, J. Eur. Ceram. Soc. 20, $321(2000)$

22. A. Bouzid, E.M. Bourim, M. Gabbay, G. Fantozzi, J. Eur. Ceram. Soc. 25, 3213 (2005)

23. S.K. Mishra, A.P. Singhi, D. Pandey, Philos. Mag. 76, 213 (1997)

24. R.F. Zhang, H.P. Zhang, J. Ma, Y.Z. Chen, T.S. Zhang, Solid State Ionics 166, 219 (2004)

25. D. Bochenek, P. Niemiec, M. Adamczyk, Z. Machnik, G. Dercz, Eur. Phys. J. B 88, 279 (2015)

26. R. Zachariasz, D. Bochenek, Eur. Phys. J. B 88, 296 (2015)

27. P. Niemiec, R. Skulski, D. Bochenek, P. Wawrzała, Phase Transit. 86, 267 (2013)

28. R. Zachariasz, J. Ilczuk, D. Bochenek, Solid State Phenom. 89, 303 (2003)

29. D. Bochenek, R. Zachariasz, Phase Transit. 88, 799 (2015)

30. K.R.M. Rao, A.V.P. Rao, S. Komarneni, Mater. Lett. 28, 463 (1996)

31. R.F. Zhang, J. Ma, L.B. Kong, Y.Z. Chen, T.S. Zhang, Mater. Lett. $\mathbf{5 5}, 388$ (2002)

32. H. Hirashima, E. Onishi, M. Nakagowa, J. Non-Cryst. Solids 121, 404 (1990)

33. T.R.N. Kutty, R. Balachandan, Mater. Res. Bull. 19, 1479 (1984)

34. L.B. Kong, J. Ma, H.T. Huang, W. Zhu, O.K. Tan, Mater. Lett. 50, $129(2001)$

35. A.S. Karapuzha, N.K. James, H. Khanbareh, S. van der Zwaag, W.A. Groen, Ferroelectrics 504, 160 (2016)

36. O. Raymond, R. Font, N. Suárez-Almodovar, J. Portelles, J.M. Siqueiros, J. Appl. Phys. 97, 084107 (2005)

37. L.M. Hrib, O.F. Caltun, J. Alloy. Compd. 509, 6644 (2011)

38. L.B. Kong, J. Ma, Mater. Lett. 51, 95 (2001)

39. X. Yang, J. Zhou, S. Zhang, J. Shen, J. Tian, W. Chen, Q. Zhang, Ceram. Int. 41, 1657 (2015) 